\title{
Confirm high standard basic farmland area: a case study in Huaihua city
}

\author{
Junling QIAO' ${ }^{1 a}$, Dafang WU²b, Yinjie $\mathrm{HE}^{2 \mathrm{c}}$
}

1. Guangdong Guang liang measurement land real estate appraisal and land use planning company Limited, Dongguan 523073, China; 2. Institute of Land Resources and Urban-Rural Planning, College of Geographical Sciences, Guangzhou University, Guangzhou 510006, China; aAuthor email: 452153606@qq.com, bCorresponding author email: wudaf2004@163.com, cemail: Terrence17@163.com

Keywords: High standards of basic farmland; The construction of key areas ; Multi-factor comprehensive evaluation method; Huaihuai city

Abstract. Accelerate the construction of a high standard of basic farmland is the primary task of the implementation of the National Land remediation planning, delineation of the high standard of construction of basic farmland in key areas is an important content of the high standard of construction of basic farmland. According to the delineation of high standards in the key areas of the construction of basic farmland contiguous focus on the infrastructure, people in local government, actively cooperate with the principles and the actual situation of Huaihua City, the use of multi-factor comprehensive evaluation method, select the new arable land potential, infrastructure conditions, soil quality, hydrological conditions, incline level, focus on contiguous rows and people ranking disposable financial resources, the seven pairs of high standards of construction of basic farmland in key areas delineated factors have a greater impact as the evaluation index, the use of AHP to determine the index weights. Huaihua City counties (cities, districts) evaluation to quantify and to finalize a comprehensive evaluation score and score high five counties (cities) is classified as a high standard of construction of basic farmland in key areas Huaihua City, and by means of GIS implementation of the high standard of construction of basic farmland in key areas on the map to determine its spatial distribution.

\section{Introduction}

Cultivated land resource is very precious, but being susceptible to damage, as an agricultural country, China's development cannot leave the cultivated land, cultivated land occupies the important position in China, is an important guarantee of people's life, but because of various reasons, the quality and quantity of cultivated land in constant decline and reduce. Pressing against China's arable land use situation this situation, The National Land Renovation Plan (2011-2015), put forward the construction of high standard basic farmland.

High standard basic farmland must first confirm the construction of high standard farmland area, this is the first step in the construction of high standard farming takada, also is the core content of construction of high standard basic farmland. Based on agricultural land grading results, analysis of the construction of high standard basic farmland potential, USES the multi-factor comprehensive evaluation method, set up a perfect evaluation index system, combining with using the method of the combination of qualitative and quantitative methods, high standard basic farmland construction, Huaihua city, determine the layout of the key areas. Through the screening process evaluation index system of high standard basic farmland looks remarkably, ensure the good quality, in the later period strictly protect arable land quality has far-reaching significance, and can achieve high standard basic farmland conversion from quantity management to quality management.

Although the home on the policy emphasizes the high standards for the construction of basic farmland, but there is currently no unified specification of high standard basic farmland construction standard. Such as Li Geng(2006), starting from the connotation and characteristics of basic farmland, build the delimit the evaluation index system of basic farmland ${ }^{[1]}$, Xiang-bin kong and others (2008) on the basis of agricultural land use, etc. Don't work, combined with using cluster analysis and 
geographic information system and means for the protection of basic farmland demarcated and study ${ }^{[2]}$.Related research and the definition of the characteristics of the fringe area of basic farmland function and delimit method research, the use of GIS technology in the county land use planning revision work defined fields of basic farmland, based on basic farmland demarcated agricultural land consolidation planning, etc. ${ }^{[3-4]}$.Domestic scholars mainly made a research of basic farmland demarcated method, however, there is little literature is the study of how to delimit the construction of high standard basic farmland area.

\section{Geographical position}

Huaihua city is located in the west of Hunan province, mountain peaks overlapping, complex terrain, show more word pattern. In southeastern south ridges constitute a barrier of nanling, successful circular entrenched xuefeng mountain, from west to the northeast of wuling mountains in northwest.70.62\% were mountain, covers an area of $1946479.00 \mathrm{hm}^{2}$, and hills, downland and plains, area of $492822.00 \mathrm{hm}^{2}, 112456.00 \mathrm{hm}^{2}$ and $117417.00 \mathrm{hm}^{2}$, respectively, $17.88 \%, 4.08 \%$ and $4.26 \%$ of the total land area, basin area at least, only $16262.00 \mathrm{hm}^{2}$, accounts for only $0.59 \%$.

\section{Methodology}

Analytic Hierarchy Process(AHP). The method is to decompose the elements related to into goals, rules, plans and so on level. Based on this to construct judgment matrix, calculate a level to other level a related index weight after normalization processing ${ }^{[5]}$.

\section{High standard basic farmland demarcated evaluation model.}

1) According to high standards of key areas defined on the basis of basic farmland construction, and combining the Huaihua city mountain area than the big, wide distribution of farmland, incomplete infrastructure, the actual situation of the uneven distribution of water resources, this article selects the new cultivated land potential, infrastructure conditions, soil quality, hydrology conditions, grade level, concentrated degree, and per capita disposable financial resources as a key area of high standard basic farmland construction evaluation index.

2) Various counties (city, area) comprehensive evaluation score is equal to the added cultivated land potential score score multiplied by the weight multiplied by the weight and infrastructure conditions and soil quality score multiplied by the weight and hydrological conditions score multiplied by the weight and grade level multiplied by the weight plus concentrated degree score multiplied by the weight and the per capita disposable financial resources score multiplied by weight.

3) Using ArcGIS technology as key areas for the construction of high standard basic farmland by the space analysis, high standard basic farmland construction, to focus on regional distribution.

\section{Data}

This information includes: the National Land Renovation Plan, High Standard Basic Farmland Construction Norms, Huaihua City Land Use Planning (2006-2020), Huaihua city land renovation plan, various counties (city, area) of the farmland classification technical report, Huaihua city, as well as social and economic statistical data assembly. Huaihua city land utilization data and social economic data, various counties (city, area) the land survey data and achievements of farmland classification data. Including Huaihua city land utilization and land reclamation plan. Due to dispersion of the collected data is need to gather the data extraction need further. And access to the map data is MapGIS format, and the key areas of high standard basic farmland construction work for ArcGIS software platform, so the need for data format conversion, convert MapGIS format of the data to ArcGIS SHP format of the data. 


\section{Results}

Result of AHP. Using special software Yaahp which is used to deal with analytic hierarchy (AHP), combined with judgment matrix, the related results are shown in table 1.

Table 1 The evaluation index weight table

\begin{tabular}{cccccccc}
\hline Index & $\begin{array}{c}\text { The new } \\
\text { cultivated land } \\
\text { potential }\end{array}$ & $\begin{array}{c}\text { Infrastru } \\
\text { cture } \\
\text { conditio } \\
\text { ns }\end{array}$ & $\begin{array}{c}\text { Soil } \\
\text { quality }\end{array}$ & $\begin{array}{c}\text { Hydrol } \\
\text { ogical } \\
\text { conditi } \\
\text { ons }\end{array}$ & $\begin{array}{c}\text { Grade } \\
\text { level }\end{array}$ & $\begin{array}{c}\text { Concent } \\
\text { rated } \\
\text { degrees }\end{array}$ & $\begin{array}{c}\text { Per capita } \\
\text { disposable } \\
\text { financial } \\
\text { resources }\end{array}$ \\
\hline weight & 0.08 & 0.04 & 0.08 & 0.19 & 0.19 & 0.39 & 0.03 \\
\hline
\end{tabular}

Huaihua city high standard basic farming takada construction key areas. According to the mentioned method in section 3, combined with high standard basic farmland demarcated evaluation model, it is concluded that shown in table 2:

Table 2 Various counties (city, area) comprehensive evaluation score

\begin{tabular}{ccccccccc}
\hline County & $\begin{array}{c}\text { New } \\
\text { cultivated } \\
\text { land } \\
\text { potential } \\
\text { score }\end{array}$ & $\begin{array}{c}\text { Score } \\
\text { infrastructure } \\
\text { conditions }\end{array}$ & $\begin{array}{c}\text { Soil } \\
\text { quality } \\
\text { score }\end{array}$ & $\begin{array}{c}\text { Hydrology } \\
\text { score }\end{array}$ & $\begin{array}{c}\text { Grade } \\
\text { level } \\
\text { score }\end{array}$ & $\begin{array}{c}\text { Concent } \\
\text { rated } \\
\text { degree } \\
\text { score }\end{array}$ & $\begin{array}{c}\text { Per capita } \\
\text { disposable } \\
\text { financial score }\end{array}$ & $\begin{array}{c}\text { Comprehensive } \\
\text { evaluation score }\end{array}$ \\
\hline Hecheng District & 80 & 100 & 60 & 60 & 100 & 73.85 & 95 & 77.25 \\
Hongjiang city & 80 & 80 & 90 & 60 & 80 & 93.63 & 95 & 82.76 \\
Zhongfang county & 80 & 100 & 80 & 80 & 80 & 82.67 & 65 & 81.39 \\
Chenxi county & 100 & 80 & 100 & 60 & 100 & 87.52 & 85 & 86.28 \\
Mayang county & 80 & 80 & 90 & 100 & 60 & 63.74 & 75 & 74.30 \\
Yuanling county & 60 & 60 & 70 & 100 & 80 & 89.00 & 65 & 83.65 \\
Xupu county & 80 & 100 & 100 & 80 & 100 & 96.85 & 70 & 92.47 \\
Jingzhou county & 80 & 100 & 90 & 80 & 60 & 78.47 & 85 & 77.35 \\
Zhijiang county & 60 & 80 & 60 & 80 & 60 & 42.02 & 65 & 57.73 \\
Huitong county & 100 & 60 & 70 & 80 & 40 & 46.86 & 100 & 60.07 \\
Tongdao county & 100 & 60 & 80 & 60 & 40 & 58.68 & 75 & 60.93 \\
Xinhuang county & 80 & 60 & 60 & 60 & 40 & 59.45 & 70 & 57.88 \\
Hongjiang area & 60 & 80 & 60 & 80 & 80 & 72.46 & 70 & 73.56
\end{tabular}

Combined with the actual situation of Huaihua city, and ultimately determine the comprehensive evaluation scores greater than 80 points, Huaihua city, county (city, area) for high standard basic farmland construction key areas. Filter the results for Xupu county, Chenxi county, Yuanling county, Hongjiang area, Zhongfang county. So defined the five counties (cities) the key area for the high standards of basic farming takada, Huaihua city construction.

\section{Conclusions}

In this paper, we diagnosed Confirm high standard basic farmland area in Huaihua based on the methodology presented in section 3 using ArcGIS. Main results are concluded below:

(1) The construction of evaluation index system combining with the principle of draw, and give full consideration to the study the characteristic of natural conditions and land use area, so as to improve the scientific of the evaluation results.Based on the principle of the key areas of high standard basic farmland construction, and considering the uneven distribution of water resources, serious pollution, Huaihua city, mountain area is in the majority of cases, the final selection of new coefficient 
of cultivated land, infrastructure conditions, soil quality, hydrology conditions, grade level, concentrated and per capita disposable financial resources as evaluation indexes.

(2) Determined by a weighted sum comprehensive evaluation score of each county (city, area), through comprehensive evaluation score higher in merit of county (city, area) in the key area for the high standard basic farmland construction, high standard basic farmland construction of Huaihua city is divided intoXupu county, Chenxi county, Yuanling county, Hongjiang area, Zhongfang county areas.

\section{Acknowledgements}

This work was financially supported by the National Natural Science Foundation of China(41101078), Guangdong education department innovative projects(2014KTSCX090), Guangdong education scientific research "twelfth five-year" rules Row 2013 annual research project (2013JK134), Guangzhou "twelfth five-year" plan philosophy and social science(15Q28), the quality of undergraduate education and teaching reform project of guangdong province "Real estate management" high-quality goods resource sharing class, Guangzhou university demonstration experiment project 2015 "geographic information system application in land use planning" and College students' innovative training at the provincial level in guangdong province department of education Project (No.201611078085, CX2015025).

\section{References}

[1] Li G, Wu C F, Cao S S, 2008. Study of index system of basic farmland demarcated. Journal of agricultural engineering, 23(1):66-71. (in Chinese)

[2] Sun X B, Jing J, Liu Y, et al. 2008. Based on the agricultural land use and other basic farmland protection areas designated. Journal of agricultural engineering 24(10):46-51. (in Chinese)

[3] Shen M, Chen F X, Su S Q, et al.2010. High standard basic farmland construction at the provincial level key zoning method research: based on the empirical analysis of guangdong province. China's land proceedings, 26(7):56-63. (in Chinese)

[4] Liu Y Y, Wu D F, Wang C H, 2011. Wetland ecological security evaluation is reviewed. Geography and Geographic Information Science, (01):69-75. (in Chinese)

[5] Wu D F, Liu Y Y, Liu Y H, et al.,2015. The prospect of research cultivated land ecological security evaluation. Journal of Chinese Ecological Agriculture, (03):257-267. (in Chinese) 